\title{
Yenilenebilir Enerji Projelerine Yönelik Güncel Yatırım ve Finansman Modelleri: Karşılaştırmalı Bir Değerlendirme
}

\author{
Vedat Akdağa, Mustafa Gözen ${ }^{\mathrm{b}, \mathrm{c}}$
}

\section{Özet}

Dünyanın pek çok ülkesinde yenilenebilir enerji yatırımlarının ve toplam elektrik üretiminde yenilenebilir enerji kaynaklarının payının artırılması amacıyla çeşitli yatırım ve finansman modelleri uygulanmaktadır. Bu modellere örnek olarak sabit fiyat garantisi, prim garantisi, yeşil sertifika, ihale ve açık eksiltme, sayaç ölçümüne dayalı tasarım, proje finansmanı, üçüncü taraf sahipliği, enerji kooperatifi, paya dayalı kitle fonlaması, yeşil tahvil ve yenilenebilir enerji fonu verilebilir. Bu makalede bu modeller, yapısı ve işleyişi dikkate alınarak karşılaştırmalı olarak incelenmiştir. Söz konusu modellerden sabit fiyat garantisi, prim garantisi ve yeşil sertifika tek başına ya da diğer modeller ile birlikte uygulanabilen modellerdir. Paya dayalı kitle fonlaması ve yeşil tahvil, etkin işleyen bir piyasada söz konusu üç modele bağımlı olmaksızın uygulanabilecek modellerdir. Sabit fiyat garantisi ve prim garantisi yerine ihale ve açı eksiltme modelleri giderek artan bir şekilde kullanılmaktadır. Bunun yanında, küçük ölçekli tesisler için sayaç ölçümüne dayalı tasarım tercih edilmektedir.
Anahtar Kelimeler

Yenilenebilir Enerji

Elektrik Piyasası

Proje Finansmanı

Yatırım Modeli

Makale Hakkında

Geliş Tarihi: 24.10.2019

Kabul Tarihi: 12.10.2020

Doi: 10.18026/cbayarsos.637375

\section{Current Investment and Financing Models for Renewable Energy Projects: A Comparative Assessment}

\begin{abstract}
In many countries of the world, various investment and financing models are applied to support renewable energy investments and increase the share of renewable energy resources in total electricity generation. Examples of these models are feed-in tariff, feed-in premium, green certificate, tender and auctioning, the design based on meter measurement, project finance, third party ownership, energy cooperative, equity crowdfunding, green bonds, and renewable energy fund. In this article, these models are examined in a comparative manner, considering their structure and functioning. Among these models, feed-in tariff, feed-in premium, and green certificate models can be solely applied or in combination with other models. Equity crowdfunding and green bonds are noteworthy as the models that can be implemented in an effectively functioning market independent from the previous three models. Tender and auction models are increasingly being used in place of feed-in tariff and feed-in premium. In addition, the design based on meter measurement is preferred for small-scale plants.
\end{abstract}

Keywords

$$
\begin{array}{r}
\text { Renewable Energy } \\
\text { Electricity Market } \\
\text { Project Finance } \\
\text { Investment Model }
\end{array}
$$

\section{About Article}

Received: 24.10 .2019

Accepted: 12.10 .2020

Doi: 10.18026/cbayarsos.637375

\footnotetext{
a Enerji Uzmanı, Enerji Piyasası Düzenleme Kurumu, Ankara, ORCID: 0000-0001-9346-8339

b Dr., Emekli Grup Başkanı, Enerji Piyasası Düzenleme Kurumu, Ankara, ORCID: 0000-0002-5195-757X

c İletişim Yazarı: mgozen@gmail.com
} 


\section{Giriş}

Yenilenebilir enerji kaynakları, oluşum açısından doğada süreklilik arzeden ve fosil enerji kaynakları gibi tükenme riski bulunmayan kaynaklardır. Ayrıca, sera gazı salımı ve çevresel etkilere karşı kaygılar dikkate alındığında temiz enerji kaynakları olarak da adlandırılmaktadır. Elektrik üretiminde bu kaynakların kullanımındaki artış, hem ülkelerin enerjide dışa bağımlılıklarını azaltmakta hem de enerji ithalatı sonucu ortaya çıan dış ticaret açığını azaltıcı yönde katkıda bulunmaktadır. Yenilenebilir enerji kaynaklarının kullanımı, iklim değişikliği sorunuyla mücadelede en önemli faktörlerden biri olarak kabul edilmektedir.

Elektrik piyasasında elektrik üretiminde kullanılan kaynağın türünden bağımsız olarak bir elektrik üretim projesinin ekonomik olarak yapılabilirliği için proje yaşam döngüsü boyunca elde edilen fayda ile proje maliyetinin karşılaştırılması gerekir. Bu şekilde yapılacak bir karşılaştırma, kural olarak yatııım kararının da temelini oluşturmaktadır. Yatırım kararı; esas itibarıyla projenin sermaye maliyeti, yakıt maliyeti ve finansman maliyetine bağlıdır. Yatırım kararı alabilmek için projenin ömrü boyunca ilgili üretim tesisinde üretilen elektrik enerjisinden sağlanacak faydanın, aynı ömür süresinde proje için katlanılacak maliyetinden fazla olması gerekir. Bu nedenle, yatırım kararı alınmadan önce planlanan yenilenebilir enerji projesine ait teknoloji ile projenin gerçekleşen maliyeti ve yaşam döngüsü hakkında kesin, karşılaştırılabilir, güvenilir ve güncel bilgilere erişim sağlanması önem arzetmektedir. Yatırım için gerekli finansal araçlar ise özel veya kamu sektörü tarafından oluşturulabilir, tasarlanabilir ve uygulanabilir (Donastorg, Renukappa ve Suresh, 2017).

$\mathrm{Bu}$ makalenin amacl, yenilenebilir enerji kaynaklarının geliştirilmesi ve kullanımının yaygınlaştırılması için güncel durumda uygulanan yatırım ve finansman modellerini karşılaştırmalı olarak incelemek ve değerlendirmektir. Bu kapsamda modellerin yapısı ve işleyişi bütünsel bir yaklaşımla ele alınmış ve uygulamada öne çıkan modellere ilişkin değerlendirmede bulunulmuştur.

\section{Yenilenebilir Enerji Projeleri ve Finansmanı}

Yenilenebilir enerji teknolojilerinin halen gelişmekte olması nedeniyle ilk yatırım maliyeti oldukça yüksektir. Bu sebeple, yeni yatırımların yapılabilmesi için finansman temini yatırımcılar açısından kolay olmamaktadır. Finans sektörü; finansman kararında yenilenebilir enerji yatırımlarını diğer yatırımlardan farklı görmemekte ve üstlendiği risk çerçevesinde kredi anapara ve faiz karşılığının geri dönüşünün sağlanmasına odaklanmaktadır. Bu bakımdan risk ve getiri, herhangi bir yatırım kararının odak noktasıdır. Her çeşit yenilenebilir enerji yatırımının kendine özgü riskleri bulunmaktadır. Bu riskler; teknik, ekonomik, düzenleyici, politik ve finansal riskler olarak sıralanabilir. Finansal risklerin yüksek olduğu ülkelerde yenilenebilir enerjiye dayalı elektrik üretim tesisi yatırım maliyeti artmakta ve bu durum yeni yatırımların yapılmasını zorlaştırmaktadır. Bu bakımdan, ülkelerin yenilenebilir enerji yatırımları için uyguladığı politika ve sağladığı teşvikler, finansal risklerin azalmasını ve yatırım maliyetinin düşmesini sağlamaktadır. Ülkelerin uyguladığı yenilenebilir enerji politikaları ile bu çerçevede hazırlanan mevzuat ve teşvik mekanizmaları, yenilenebilir enerji yatırımlarının gelişim düzeyini belirleyen etmenlerin başında gelmektedir. Ülkedeki yasal çerçeveye ve teşvik mekanizmasına bağlı olarak finansman seçenekleri de çeşitlilik kazanmaktadır.

Yenilenebilir enerji projelerinin yukarıda çerçevesi çizilen özellikleri, bu tür enerji yatırımlarının piyasa şartlarına bırakılmadan devletler tarafından çeşitli teşvik mekanizmaları 
ve mevzuatlar kapsamında desteklenmesini zorunlu kılmaktadır. Güncel durum itibarıyla, yenilenebilir enerji projelerinin, özel bir yatırım ve finansman modeli olmadan serbest piyasa koşullarında tamamlanması ve varlığını devam ettirmesi henüz mümkün görülmemektedir. Bazı yenilenebilir enerji kaynağına dayalı üretim tesislerinin yatırım tutarında azalma olmakla birlikte bu gelişmelerin projelerin serbest piyasada varlığını sürdürmesi bakımından yeterli olmadığı anlaşılmaktadır.

Bu nedenle, günümüzde özellikle başlangıç aşamasında olan yenilenebilir enerji projelerinin özel düzenlemeler ile desteklenmesi gerektiği genel kabul gören bir yaklaşımdır. Çoğu ülkede yenilenebilir enerji kaynaklarına dayalı elektrik üretimi hükümetler tarafından desteklenmektedir. Bu konuda hükümetlerin destekleme yapmasının temel nedeni, yenilenebilir enerji kaynaklarına dayalı üretim tesislerinin yukarıda bahsedilen dezavantajları nedeniyle piyasada rekabet edememesidir. Bu nedenle, çoğu ülkede yenilenebilir enerji politikaları, kamu tarafından sunulan destek mekanizmalarına bağlı olarak çeşitli yasal düzenlemeler yoluyla belirlenmektedir.

\section{Yatırım ve Finansman Modelleri}

Yenilenebilir enerjiden elektrik üretimini artırmak amacıyla çeşitli yöntem, politika ve modeller geliştirilmiş ve dünyada yaygın bir şekilde kullanılmaktadır. Bu yöntem, politika ve modeller; düzenleyici nitelikteki modeller, iş modelleri ile mali teşvik ve diğer kamu destekleri olmak üzere üç ana başlık altında sınıflandırılmış ve ayrıntıları Tablo 1'de verilmiştir.

Tablo 1. Yatırım ve finansman modelleri

\begin{tabular}{ll}
\hline Yatırım ve finansman modelleri & Alt modeller \\
\hline \multirow{2}{*}{ A-Düzenleyici nitelikteki modeller } & Sabit fiyat garantisi \\
\cline { 2 - 2 } & Prim garantisi \\
\cline { 2 - 2 } & Yeşil sertifika \\
\cline { 2 - 2 } & İhale ve açık eksiltme \\
\hline \multirow{3}{*}{ B- İş modelleri } & Projeç ölçümüne dayalınansmanı tasarım \\
\cline { 2 - 2 } & Üçüncü taraf sahipliği \\
\cline { 2 - 2 } & Enerji kooperatifi \\
\cline { 2 - 2 } & Paya dayalı kitle fonlaması \\
\cline { 2 - 2 } & Yeşil tahvil \\
\cline { 2 - 2 } C- Mali teşvik ve diğer kamu destekleri & Yenilenebilir enerji fonu \\
\cline { 2 - 2 } & Elektrik satışında vergi indirimi \\
\hline & Elektrik üretimi için doğrudan ödeme \\
\hline & Kredi, hibe, sübvansiyon ve indirimler \\
\hline
\end{tabular}

Yatırım ve üretim vergisi indirimleri, elektrik satışında vergi indirimi, elektrik üretimi için doğrudan ödeme, kredi, hibe, sübvansiyon ve çeşitli konularda indirimler mali teşvik ve diğer 
kamu destekleri kapsaminda yer almaktadır. Bu kapsamdaki uygulamalar, genel olarak düzenleyici nitelikteki modelleri ve iş modellerini desteklemek amacıyla yapılmaktadır. Düzenleyici modeller kendi içinde; sabit fiyat garantisi, prim garantisi, yeşil sertifika, ihale ve açık eksiltme, sayaç ölçümüne dayalı tasarım olmak üzere beş alt başlık altında incelenebilir. Bu kapsamdaki modeller, tek başına uygulanabileceği gibi yenilenebilir enerji kaynak türü, teknoloji ve kurulu güç gibi unsurlar dikkate alınarak birden fazla model ile aynı anda da uygulanabilmektedir. İş modelleri ise kendi içinde; proje finansmanı, üçüncü taraf sahipliği, enerji kooperatifi, paya dayalı kitle fonlaması, yeşil tahvil ve yenilenebilir enerji fonu olmak üzere altı alt başlık altında incelenebilir.

Yukarıda bahsedilen modellerin dünya veya bölgesel bazda kullanım yoğunluğu hakkında genel çıkarımda bulunmak mümkün olmamaktadır. Piyasadaki gelişmeler ve ekonomik koşullar dikkate alınarak uygulanan modellerde zamanla değişikliğe gidildiği görülmektedir (REN21, 2020). Tercih edilen bir modelin performansı ve içinde bulunan koşullar modellerde değişiklik yapılmasını ve/veya yeni model uygulanmasını gerektirebilmektedir. Seçilmiş bazı ülkelerde uygulanan yatırım ve finansman modelleri Tablo 2 ' de verilmiştir.

Tablo 2. Ülkeler bazında yatırım ve finansman modelleri

\begin{tabular}{|c|c|c|c|c|c|}
\hline Ülkeler & $\begin{array}{l}\text { Sabit fiyat } \\
\text { garantisi }\end{array}$ & $\begin{array}{c}\text { Prim } \\
\text { garantisi }\end{array}$ & Yeşil sertifika & İhale & $\begin{array}{c}\text { Sayaç ölçümüne } \\
\text { dayalı model }\end{array}$ \\
\hline Almanya & $\checkmark$ & $\checkmark$ & & $\checkmark$ & $\checkmark$ \\
\hline Çin & $\checkmark$ & & $\checkmark$ & & \\
\hline \multicolumn{6}{|l|}{$\mathrm{ABD}$} \\
\hline Kaliforniya & $\checkmark$ & & & & $\checkmark$ \\
\hline New York & & & & & $\checkmark$ \\
\hline Slovakya & $\checkmark$ & & & & \\
\hline İsveç & & & $\checkmark$ & & \\
\hline İrlanda & $\checkmark$ & & & & \\
\hline Fransa & $\checkmark$ & & & $\checkmark$ & \\
\hline Avustralya & & & $\checkmark$ & & $\checkmark$ \\
\hline Japonya & $\checkmark$ & & & & \\
\hline Türkiye & $\checkmark$ & & & $\checkmark$ & $\checkmark$ \\
\hline
\end{tabular}

Kaynak: Akdağ ve Gözen (2019)

Tablo 2' den de görüleceği üzere, modellerin geniş bir uygulama alanı olduğu anlaşılmaktadır. Söz konusu modeller tek başına uygulandığı gibi birden fazla modelin birlikte uygulanması da mümkündür. Hatta birden fazla model, aynı yenilenebilir enerji kaynağ 1 için kullanılabilmektedir. Bu amaçla, öncelikle büyük ve küçük ölçekli üretim tesisleri tanımı yapılmakta ve her iki grup için farklı model uygulanabilmektedir.

\section{Sabit Fiyat Garantisi}

Sabit fiyat garantisi, yenilenebilir enerji kaynağına dayalı elektrik üretim tesisinde üretilen ve elektrik şebekesine verilen her birim elektrik enerjisi için ilgili üreticiye ödenen sabit tutara karşılık gelmektedir. Bu kapsamdaki ödemeler, ilgili yenilenebilir enerji projesinin ekonomik 
ömrü dikkate alınarak belli bir süre için, genellikle 10-25 yıl arasında garanti edilmektedir. Bu konuda başka bir yaklaşım, ilgili üretim tesisinin tam verimli olarak çalışabileceği maksimum bir sürenin belirlenmesi ve bu süre boyunca ödeme yapılmasıdır. Elektrik bedeli, genellikle şebeke, sistem veya piyasa işletmecisi tarafından yatırımcı ile imzalanan sözleşme çerçevesinde yapılmaktadır (Energypedia, 2019a).

$\mathrm{Bu}$ modelde fiyatlar genellikle, yenilenebilir enerji kaynağına dayalı elektrik üretim tesisinde üretilen seviyelendirilmiş elektrik maliyetinin (LCOE) hesaplanması temelinde belirlenmektedir. LCOE, bir elektrik üretim santralinin finansman, bakım, işletme vb. harcamaları dikkate alınarak hesaplanan elektrik birim maliyetidir. Başka bir deyişle, maliyeti karşılamak için elektriğin satılması gerektiği en düşük fiyattır (NREL, 2019). Ayrıca yenilenebilir enerji teknolojileri arasındaki maliyet farklılıkları da dikkate alınarak her teknoloji için ayrı bir alım garantisi fiyatı uygulanmaktadır. Bununla birlikte, küçük ve orta ölçekli yenilenebilir enerji projelerinin yüksek üretim maliyetini yansıtan ve yenilenebilir enerji projesinin büyüklüğü dikkate alınarak kurulu güce göre ikinci bir fiyat farklılaşması da yapılabilmektedir. Üçüncü olarak, yenilenebilir enerji proje sahasına göre, o bölgede kullanılacak enerji kaynağı potansiyeli doğrultusunda fiyat farklılaştırması da yapılabilmektedir. Bu duruma, ortalama rüzgar hızı baz alınarak yapılan fiyat farklılaştırması örnek gösterilebilir. Couture, Cory, Kreycik ve Williams'a (2010) göre bu modelin uygulanmasında alım fiyatının belirlenmesinde teknoloji, kurulu güç ve tesis sahası gibi seçeneklerin bir karışımı uygulanabilmekle birlikte, bu durum destek programının maliyetini artırma riskini de beraberinde getirmektedir.

Sabit fiyat garantisi, projenin işletmeye alınmasından sonra, garanti edilen tüm ödeme süresi boyunca uygulanmaktadır. Bazı durumda, ilk yıllarda daha yüksek, geri kalan yıllarda daha düşük fiyat ödemesi yapılabilmektedir. Bu yöntem sermaye yoğun yenilenebilir enerji projelerinin finansmanını kolaylaştırmaktadır. Bu durumun tersi olan uygulamada, işletme ve bakım maliyetlerindeki artışı karşılamak için alım garantisi fiyatı yıllık bazda artırılabilmektedir (Energypedia, 2019a).

Bu modelde alım garantisi tarifeleri, genellikle yenilenebilir enerji mevzuatı kapsamında veya bağımsız düzenleyici kurumlar tarafından belirlenmektedir. Bu durum, alım garantisi fiyatının güncellenmesinin ek bir idari işlem gerektireceği anlamını da taşımaktadır. Bu nedenle birçok model, alım garantisi fiyatlarında düzenli aralıklarla uygulanan otomatik bir azaltma mekanizmasını da içermektedir. Bu azaltma mekanizması, belirli bir yenilenebilir enerji teknolojisi için pazar gelişimi dikkate alınarak önceden ya da piyasa gelişimine bağlı olarak sonradan da belirlenebilir (Rickerson, Laurent, Jacobs, Dietrich ve Hanley, 2012). Alım fiyatının azaltılması ile ilgili hesaplamada; teknolojik ilerleme, piyasa gelişimi ve teknoloji maliyetinin evrimine ilişkin veriler kullanılmaktadır. Alım fiyatında doğru tutarda azaltım yapılması, teknoloji geliştirme konusundaki belirsizlik ve finansman maliyeti gibi faktörler nedeniyle zor olabilmektedir (Deutsche Bank AG, 2010).

Türkiye'de yenilenebilir enerji kaynağına dayalı elektrik üretimi, 18/05/2005 tarihli ve 25819 sayılı Resmi Gazete'de yayımlanarak yürürlüğe giren 5346 sayılı Yenilenebilir Enerji Kaynaklarının Elektrik Enerjisi Üretimi Amaçlı Kullanımına İlişkin Kanun kapsamında sabit fiyat garantisi kapsamında desteklenmektedir (Mevzuat Bilgi Sistemi, 2019a). Söz konusu kanun çerçevesinde, 31/12/2020 tarihine kadar işletmeye girmiş veya girecek olan yenilenebilir enerji kaynaklarına dayalı lisanslı elektrik üretim tesisleri, işletmeye girdiği tarihten itibaren 10 yıl boyunca aynı kanunun eki I sayılı cetvelde yer alan fiyatlardan yararlanabilecektir. Söz 
konusu destek mekanizmasına katılım zorunlu olmayıp ilgili yatırımcının kararına bağlı olmaktadır. 5346 sayılı Kanun eki I sayılı cetvelde yer alan fiyatlar Tablo 3'de verilmiştir.

Tablo 3. Kaynak bazında destekleme fiyatları

\begin{tabular}{lc}
\multicolumn{1}{c}{$\begin{array}{c}\text { Yenilenebilir enerji } \\
\text { kaynağı }\end{array}$} & $\begin{array}{c}\text { Destekleme fiyatı } \\
\text { (ABD Doları cent/kWh) }\end{array}$ \\
\hline Hidroelektrik & 7,3 \\
\hline Rüzgar & 7,3 \\
\hline Jeotermal & 10,5 \\
\hline Biyokütle (çöp gazı dahil) & 13,3 \\
\hline Güneş & 13,3 \\
\hline
\end{tabular}

Kaynak: Akdağ ve Gözen (2019)

5346 sayılı Kanunda I sayılı cetveldeki ilgili değere eklenmek üzere yerli aksam kullanımına ilişkin ikinci bir destek öngörülmüş olup buna ilişkin fiyatlar aynı kanunun eki II sayılı cetvelde düzenlenmiştir. Yerli aksam desteğinden yararlanabilmek için öncelikle I sayılı cetveldeki enerji desteğinden yararlanmak için gerekli şartları taşımak ve istenen bilgi ve belgeleri 5346 sayılı Kanunda belirtilen tarihe kadar online ortamda Enerji Piyasası Düzenleme Kurumuna sunmak gerekmektedir. Herhangi bir tüzel kişinin I sayılı cetvelden yararlanmadan sadece II sayılı cetvelden yararlanması söz konusu olmamaktadır.

\section{Prim Garantisi}

Prim garantisi uygulaması kapsamında, yenilenebilir enerji kaynağından üretilen elektrik spot piyasada satılır ve elektrik üreticisi, piyasa fiyatı üzerine ilave olarak satışını yaptığı elektrik için kWh başına prim alır. Prim tutarı, sabit veya piyasa fiyatına bağlı değişken olabilir. Sabit prim tutarı uygulama bakımından daha kolaydır ancak üreticilere, piyasada elektrik fiyatının yüksek olması halinde gereğinden fazla ödeme yapılması; düşük olması halinde ise yetersiz ödeme yapılması riskini içermektedir. Bu nedenle, sabit prim tutarı uygulamasında üreticiye ödenecek prim tutarı veya toplam bedel için minimum ve maksimum seviyeler belirlenmektedir. Değişken prim tutarı uygulamasında ise ödenecek prim fiyatı, kullanılan teknolojiye bağlı olarak belirli bir süre boyunca oluşan piyasa fiyatı ile önceden tanımlanmış bir referans tarife seviyesindeki fark olarak düzenli bir şekilde hesaplanmaktadır. Piyasa fiyatı referans tarifeden yüksekse, prim ödemesi yapılmamaktadır. Piyasa fiyatının düşük olması halinde yenilenebilir enerji üreticisini korumak için prim garantisi olarak kullanılan asgari bir piyasa fiyatı da uygulanmaktadır (Energypedia, 2019b).

$\mathrm{Bu}$ model çerçevesinde yatırımcıya ödenecek prim, sabit fiyat garantisi uygulamasında olduğu gibi teknolojiye, üretim tesisi büyüklüğüne veya bölgelere göre farklılaştırılabilir. Ayrıca ödenecek primin üzerine kullanılan teknolojiye bağlı olarak ilave prim ödemesi yapılabilir. Bazı uygulamalarda, üreticinin spot piyasada elektriğin doğrudan satılmasıyla ilgili ek maliyetlerini karşılamak için ilave bir ödeme de yapılmaktadır. Bunun yanında, ödenecek prim tutarının seviyesi için fiyat azaltımı da yapılabilmektedir (Energypedia, 2019b).

\section{Yeşil Sertifika}

Yeşil sertifika; literatürde "yenilenebilir enerji kotası", "yenilenebilir enerji yükümlülüğ̈̈" veya "yenilenebilir portföy standartı" olarak da adlandırılmaktadır. Yenilenebilir enerji kaynağından 
üretilen her birim elektrik için yenilenebilir enerji yatırımcısına yeşil sertifika verilmekte ve sertifikanın satışı ek gelir sağlamaktadır (Lind ve Rosenberg, 2014). Söz konusu gelirin seviyesi, sertifika piyasasında işlem gören yeşil sertifikanın fiyatına bağlı olmaktadır. Yatırımcı açısından yeşil sertifika satışından elde edilen gelirin, yenilenebilir enerji kaynağından üretilen elektriğin piyasada satışından elde edilen gelir ile elektrik üretim maliyeti arasındaki farktan daha fazla olması gerekir (Energypedia, 2019d).

Bu uygulamada, elektrik tedarikçisinin piyasaya sunduğu elektrik enerjisinin veya büyük ölçekli elektrik tüketicisinin tükettiği enerjinin belli bir oranının yenilenebilir enerji kaynağına dayalı üretim tesisinde üretilmesi zorunluluğu getirilmektedir. Teknoloji çeşitliliğini teşvik etmek için farklı yenilenebilir enerji kaynak türleri için alt kotalar tanımlanabilmektedir. Bu kotalar; ulusal, bölgesel veya yerel yönetimler tarafından tanımlanmakta ve yenilenebilir enerji tesisinin gelişimini desteklemek amacıyla genellikle zaman içerisinde arttırılmaktadır (Abolhosseini ve Heshmati, 2014).

Yeşil sertifika, zorunlu veya gönüllü olmak üzere iki farklı biçimde uygulanmaktadır. Zorunlu yöntem daha yaygın uygulanmakta ve uygulama çerçevesinde tedarik şirketine belirli bir oranda portföyünde yenilenebilir üretim tesisinde üretilmiş elektrik için kota zorunluluğu getirilmektedir. Gönüllü sistemde tüketici aktif bir rol üstlenmekte, gelişmiş çevre bilincinin bir sonucu olarak yenilenebilir enerji kullanımını talep etmekte ve tedarik şirketini yenilenebilir enerji kaynağından üretilmiş elektrik temin etmeye zorlamaktadır (Gözen ve Durak, 2003).

Kota yükümlülüğü olan şirketler yenilenebilir enerji tedarikini ya kendi üretiminden ya da üçüncü taraftan sağlayabilmektedir (Beck ve Martinot, 2004). Abolhosseini ve Heshmati (2014)'e göre uygulamada çoğunlukla elektrik tedarikçisi şirketler, sertifika piyasası aracılığıyla üçüncü taraftan yeşil sertifika satın alarak kota yükümlülüğünü yerine getirme olanağına sahip olmaktadır.

Elektrik tedarikçisi şirket üzerindeki kota yükümlülüğünü yerine getirmek için ihtiyaç duyduğu kadar sertifika almak zorundadır, aksi takdirde cezalandırılmaktadır. Eksik sertifika başına düşen ceza tutarı, genellikle sertifikanın fiyatı için üst seviyeyi belirlemektedir. Yeşil sertifika, en düşük maliyetli yenilenebilir enerji teknolojisinin kullanılmasını destekleyen model olarak farklı teknolojiler arasında hiçbir fark olmayacak şekilde tek bir çeşit olabilir. Alternatif olarak, yüksek üretim maliyetine sahip yenilenebilir enerji teknolojisinden üretilen her birim elektrik enerjisi için birden fazla sertifika alınması şeklinde bir model de tasarlanabilir. Bu alternatif; Bahar, Jagoda ve Steenblik'e (2013) göre çeşitlendirilmiş yenilenebilir enerji teknoloji portföyünün geliştirilmesinde olumlu etkisine sahiptir.

\section{İhale ve Açık Eksiltme}

Bu model çerçevesinde, temel niteliği önceden idare tarafından belirlenen yenilenebilir enerji yatırımı için ihale veya açı eksiltme yoluyla yatırımc belirlenmektedir. Bu tür yatırımcı seçimi, elektrik üretim maliyetine dayanan rekabetçi bir mekanizmadır. Açık eksiltmede yatırımcı seçiminde fiyat tek kriterdir, ihalede ise yatırımcı seçiminde fiyat yanında ek kriterler kullanılır. Yatırımcı seçimi, tasarıma bağlı olarak elektrik üretim tesisi kurulu gücü veya elektrik üretim miktarı üzerinden yapılabilir. Kazanan teklif sahibi yatırımcıya verilen destek; sabit fiyat garantisi, prim garantisi, kapasite ödemesi, sertifika fiyatı veya yatırım hibesi şeklinde olabilmektedir. Lucas, Ferroukhi ve Hawila (2013) tarafından vurgulandığı üzere bu 
tür ihaleler, belirli bir enerji kaynağına dayalı olarak gerçekleştirilebileceği gibi kullanılan enerji kaynağından bağımsız da gerçekleştirilebilir.

Belirlenen kurulu güç kapasitesi veya elektrik üretim miktarı için yatırımcı seçimi genellikle çok katılımlı açık eksiltme şeklinde olmaktadır. Bu yönteme göre, ayrı uygulamalar şeklinde birden fazla belirlenen MW cinsinden kurulu güç kapasitesi veya MWh cinsinden elektrik üretim miktarı içinverilen birden fazla teklif, en düşük teklif fiyatından başlanarak birim fiyata göre sıralanır ve belirlenen kurulu güç veya elektrik üretim miktarı teklif sahiplerine tahsis edilir. Bazı uygulamalarda, önceden tanımlanmış tek bir proje için ihale veya açık eksiltme yoluyla yatırımcı seçimi yapılabilmektedir. Bu konuda belirli bir sahada rüzgar enerjisine dayalı üretim tesisi kurulumu için ihale veya açık eksiltme süreci örnek verilebilir.

İhale sisteminde teklif sahipleri, ihaleye katılabilmek için genellikle bazı kriterleri yerine getirmek zorundadır. Bu kriterler; teklif verecek kişiyle ilgili satış hacmi, iş referansı ve finansal durumu ile teklife konu projeye ilişkin teknik veya ticari gerekliliklerin yerine getirilmesi ve söz konusu proje için gerekmesi halinde lisans ve izinlerin alınmasını içerebilir. Bu kriterler; ön yeterlilik aşamasında veya nihai tekliflerin değerlendirilmesi sırasında dikkate alınabilir. Ayrıca teminat garantisi, teklif veren katılımcıların hepsinden veya yalnızca başarılı katılımcılardan istenebilir. İhale ile seçilen bir projenin gerçekleşmemesi veya sürecin gecikmesi durumunda, bu teminatlara el konulabilir veya diğer ceza türleri olarak sözleşme feshi, destek miktarının azaltılması, destek süresinin kısaltılması veya mali cezalar uygulanabilir. Bu noktada, Abdmouleh, Alammari ve Gastli'nin (2015) vurguladığı üzere, yatırımcının kendisinden kaynaklanan gecikmeler ile sorumluluğu dışında mücbir sebepler sonucu yaşanan gecikmeler arasında net bir ayrım yapılması ve buna göre yaptırım yoluna gidilmesi önem arz etmektedir.

Açık eksiltmede teklifler kapalı zarf içerisinde sunulur ve açıklanmaz, bundan dolayı her bir teklif sahibi tarafından rakiplerin teklifi bilinmeden ve bunlara tepki vermeden teklif verilmiş olunur. Açık eksiltmede fiyat bütün teklif sahipleri için en yüksek başarılı teklifin fiyatı olarak homojen bir şekilde belirlenebilir veya teklif edilen her fiyat başarılı fiyatın altında olmak kaydıyla, teklif edilen fiyat üzerinden ödüllendirme yapılabilir. Açık eksiltmede teklifler katılımcılara açık olarak sunulur ve en düşük maliyetli fiyat belirleninceye kadar diğer teklif sahiplerine aşağı doğru yeni teklif verme imkanı sağlanır. Bu tür açık eksiltmede, çok yüksek maliyetlere yol açacak beklenenden düşük ve gerçek dışı teklif riskini ortadan kaldırmak için idare tarafından asgari fiyat limitleri belirlenebilir (Energypedia, 2019ç).

Türkiye'de 5346 sayılı Kanunun 7 nci maddesinin dördüncü fıkrası çerçevesinde, sadece rüzgar ve güneş enerjisine dayalı başvurularda aynı bağlantı noktasına ve/veya aynı bağlantı bölgesine bağlanmak için birden fazla lisans başvurusunun bulunması hâlinde, Türkiye Elektrik İletim A.Ş. tarafından en düşük fiyatın teklif edilmesi esasına dayanan yarışma yapılacağ1 düzenlenmiştir (Mevzuat Bilgi Sistemi, 2019a). Bunun yanında, Yenilenebilir Enerji Kaynak Alanları Yönetmeliğinde Enerji ve Tabii Kaynaklar Bakanlığı tarafından yenilenebilir enerji kaynak alanlarında yatırım yapacak yatırımcının seçimi ve yatırımcıya uygulanacak destekleme fiyatının ihale yoluyla belirleneceği düzenlenmiştir (Mevzuat Bilgi Sistemi, 2019b).

\section{Sayaç Ölçümüne Dayalı Tasarım}

Sayaç ölçümüne dayalı modelin genel amac1; yenilenebilir enerji kaynaklarının doğası gereği belirli gün veya mevsimlerde bu kaynaklardan üretilen elektrik enerjisinin bol olması ve bu kaynaklardan üretilen elektriğin tüketicinin elektrik talebini aşması durumunda, ihtiyaç 
fazlası elektrik enerjisinin değerlendirilerek yatırımlar için teşvik oluşturmasıdır. $\mathrm{Bu}$ uygulama, kullanıcıların yaşadıkları yerde yenilenebilir enerji kaynaklarından ürettikleri, ancak tüketmedikleri elektrik enerjisi için, kredi veya ödeme alabilmelerine imkan sağlayarak küçük ölçekli yenilenebilir enerji sistemlerinin dağılımını ve yaygınlaşmasını desteklemek amacıyla kullanılmaktadır. Başka bir deyişle, üretici durumunda olan tüketicinin ürettiği fazla enerji şebekeye verilmekte ve miktarı ölçülmektedir. Bu şekilde şebekeye verilen elektrik için sistemde kredi tanımlanmakta ve bu kredi daha sonra tüketilecek elektrikten düşülmektedir (DSIRE, 2019). Sayaç ölçümüne dayalı işleyiş ülkeden ülkeye farklılık göstermekle beraber, pek çok ülkede elektrik enerjisinin kullanımının dengelenmesine ve yenilenebilir enerji kaynağından elektrik üretiminin teşvik edilmesine katkı sağlamaktadır (IEA, 2014).

Bu uygulama, tüketici tarafından küçük ölçekli üretim tesisinde üretilen elektriğin, söz konusu tüketicinin uhdesindeki tüketim noktasında tüketimi ile dengelendiği bir sistemdir (DSIRE, 2019). Bu uygulama bazı ülkelerde bir gelir kaynağı olarak tasarlanmakta; bazı ülkelerde ise kullanıcının ürettiği ihtiyaç fazlası elektriğin belli bir fiyattan satılmasına ve bu satış için kullanıcıya ödeme yapılmasını öngören bir sistem olarak düzenlenmiştir (IEA, 2014).

Bu model küçük ve orta ölçekli yenilenebilir enerji tesisleri için uygulanmakta olup bu uygulamanın işleyebilmesi için kullanıcının şebekeye bağlanmasına izin veren teknik prosedür ve kolaylaştırılmış idari sürecin düzenlenmesi gerekmektedir. Rüzgar ve güneş enerji sistemlerinde sık rastlanan bu uygulama iki yönlü elektrik sayacı şeklindeki bir mekanizmanın şebekeye paralel çalışması prensibine göre işletilmektedir. Elektrik sayaçları hem elektrik tüketimini hem de kullanıcılar tarafından sisteme verilen elektriği kayıt altına almaktadır. Kullanıcıların ilgili dönem sonunda sisteme verdiği fazla elektrik veya tükettiği fazla elektrik sayaçla ölçülerek kullanıcının elektrik faturasına yansıtılmaktadır. Bu uygulamayla kullanıcı tüketimini dengede tutabilir, elektrik üretimini dengeli bir şekilde gerçekleştirebilir ve sisteme verdiği fazla elektrik üzerinden ödeme alabilir (Liptow ve Remler, 2012). Mahsuplaşma saatlik, aylık veya yıllık olarak yapılabilir.

Bu model; net ölçüm ve net faturalandırma olmak üzere iki alt gruba ayrılabilir. Net ölçüm modelinde; yenilenebilir enerji kaynaklarından elektrik üreticisi, ürettiği ve tükettiği elektrik üzerinden yapılan hesaplamalar çerçevesinde faturalandırılır ve üretimin tüketimden fazla olduğu süreçler için alternatif olarak ya sistemden faturaya yansıtılacak şekilde ödeme alır ya da bu enerjinin karşılığında tüketim hakkı kazanır (Eid, Guillén, Marín ve Hakvoort, 2014). Bu yönteme dayalı politikalarda, üretilen elektriğin artakalan kısmı sübvansiyon kapsamında yüksek alım fiyatları üzerinden sisteme satılmakta ve ancak bu sübvansiyonun maliyeti bütün tüketicilere yansıtıldığı için tepkilerle karşılaşılmaktadır (Comello ve Reichelstein, 2017).

Net faturalama yönteminde üretilen elektriğin tamamı belirlenen alım garantisi fiyatı üzerinden sisteme satılmaktadır. Bu model, özellikle çatı kiralama yatırımı için uygun olup elektrik üretim ve tüketimi birbirinden farklı değerlendirilmektedir. Net faturalama uygulamasında çatı sahibine mevcut elektrik aboneliği çerçevesinde tedarikçisi tarafından tüketim faturası kesilmesine devam edilmektedir. Kiralama ile çatı üzerinde elektrik üretim tesisi kuran yatırımcı ise ürettiği elektrikten elde ettiği gelirin belirli bir oranını veya sabit bir fkira bedelini çatı sahibine ödemektedir.

Türkiye'de Elektrik Piyasasında Lisanssız Elektrik Üretim Yönetmeliğinde sayaç okumasına dayalı saatlik ve aylık mahsuplaşma yöntemleri öngörülmüştür (Mevzuat Bilgi Sistemi, 2020). 
$\mathrm{Bu}$ yönetmelikte öngörülen her iki mahsuplama uygulaması esas itibarıyla net ölçüm yöntemidir. Bu kapsamda;

a- 10 kW'a kadar (10 kW dahil) yenilenebilir enerji kaynağına dayalı ve kendi tüketim tesisinin bağlantı anlaşmasındaki sözleşme gücüne kadar, üretimi ve tüketimi aynı noktadan bağlı üretim tesisleri,

b- Kamu kurum ve kuruluşları tarafından kurulan atıksu ve içme suyu arıtma tesisleri ile tarımsal sulama amaçlı tesislerin bağlantı anlaşmasındaki sözleşme gücünü geçmemek kaydıyla, tüketim tesisleri ile aynı ölçüm noktasında söz konusu yönetmeliğin 5 inci maddesinin birinci fıkrasının (c) bendi kapsamındaki yenilenebilir enerji kaynaklarına dayalı üretim tesisleri,

c- Bağlantı anlaşmasındaki sözleşme gücünü ve söz konusu yönetmeliğin 5 inci maddesinin birinci fikrasının (c) bendi uyarınca belirlenecek kurulu gücü geçmeyecek şekilde tüketim tesisi ile aynı ölçüm noktasında, dağıtım tesisi niteliğinde tesis teçhiz etmeden, yenilenebilir enerji kaynaklarına dayalı üretim tesisleri,

için aylık mahsuplaşma uygulanacaktır. Aylık mahsuplaşma dışında kalan tesisler için saatlik mahsuplaşma uygulanacaktır. Söz konusu yönetmelik çerçevesinde kurulacak üretim tesislerinin, üretim faaliyetinde bulunacak kişinin uhdesindeki en az 1 adet tüketim noktası ile ilişkilendirilmesi gerekir.

Saatlik uygulamada bir üretim tesisinin üretimi bir günün her saati için ayrı ayrı kaydedilir. Söz konusu üretim tesisi ile ilişkilendirilen tüketim noktasının günün her saati için tüketimi de aynı şekilde ayrı ayrı kaydedilir. Bir günün her bir saati için kaydedilen üretim ve tüketim miktarları karşılaştırılır. Her saat için söz konusu iki değerin farkı sıfır, pozitif veya negatif olabilir. Günlük bazda pozitif ve negatif değerler kendi aralarında toplanır. Üretim ve tüketim miktarlarının aynı olması halinde, üretim faaliyetinde bulunan kişiye elektrik enerjisi için söz konusu saat dilimi için herhangi bir bedel ödenmez. Yukarıda bahsedilen pozitif değer, ilgili üretim tesisinde üretilen ihtiyaç fazlası enerji anlamına gelir. İhtiyaç fazlası olarak sisteme verilen enerji, tüketim tesisinin abone grubuna ait perakende tek zamanlı aktif enerji bedeli üzerinden 10 yıl süre ile satın alınacaktır. Negatif değer, üretim faaliyetinde bulunan kişinin kendi üretiminin ihtiyacını karşılamadığ 1 ve tedarikçisinin elektriğini kullandığı anlamına gelir. Bu işlemler, her gün için yapılır ve faturalandırma işlemi aylık bazda yapılır. Aylık mahsuplaşmada bir ay içinde yapılan üretim ve tüketim değerleri karşılaştırılarak sonuca göre ilgilisi tarafından faturalandırma yapılır.

\section{Proje Finansmanı}

Proje finansmanı, temel olarak, borç verenin projenin gelecekteki getirisini kredinin teminatı olarak kabul ettiği bir finansman yöntemidir. Proje kredisi için teminat projenin kendisi olmaktadır. Proje finansmanı ibaresini kullanabilmek için proje özelinde bir nakit akışının bulunması ve proje ile ilgili varlıkların ayrıştırılması gerekmektedir. Proje finansmanının kullanıldığı durumlarda, sadece yatırımcı ya da borç verenler değil, projeye dahil olan tüm tarafların, proje finansmanının nasıl işlediğini, tarafların finansman sürecindeki rolünü ve finansal yapıdan nasıl etkilendiklerini bilmeleri gerekmektedir (Yescombe, 2014).

Proje finansmanında en önemli iki kural; projenin teknik olarak yapılabilir olması ve projenin kendi borcunu ödeyip borç verene belli bir düzeyde getiri sağlamasıdır. Proje finansmanında 
toplam finansmanın \%20-\%30'luk k1smı özsermayeden, \%70-\%80'lik kısmı ise finansman kuruluşundan sağlanmaktadır (Yıldırım, 2016). Bu amaç için öncelikle bir fon kurulmakta, proje için ihtiyaç duyulacak kaynak söz konusu fonda toplanmakta ve projeye bu fon kaynaklarından finans sağlanmaktadır. Proje gerçekleşmelerinden sonra projeden elde edilen gelirler ile özsermaye için temettü ve kredi geri ödemeleri yapılmaktadır. Proje finansmanında kredi miktarı ve şartları, piyasa koşullarına, finanse edilen proje çeşidine ve geliştirici tarafından projede tutulan riske bağlı olmaktadır (Yıldırım, 2016).

Proje finansmanının yapısı, sektörlere ve projelere göre farklılık göstermektedir. Ancak Yescombe (2014)'e göre bu finansman türünün genel özellikleri şunlardır. Proje finansmanı modeli proje için kurulan "özel amaçlı proje şirketi" üzerinden gerçekleştirilmektedir. Bu model yeni geliştirilen projelerde daha fazla uygulanmaktadır. Proje finansmanı çerçevesinde geri ödeme ile ilgili sorumluluk proje şirketi üzerinde olup bazı durumlarda proje şirketi sahiplerine sinırlı olarak sorumluluk yüklenebilmektedir.

\section{Üçüncü Taraf Sahipliği}

$\mathrm{Bu}$ iş modelinin esası; yenilenebilir enerji kaynağından elektrik üretim tesisinin finansman, kurulum ve işletilmesinin üçüncü kişiler tarafından yürütülmesine dayanmaktadır (Karasayar, 2017). Bu model, çatı üzerinde güneş enerjisine dayalı elektrik üretim tesisi kurulmasında tercih edilen bir model olmaktadır. Bu çerçevede, çatı sahibi ile çatı üzerinde üretim tesisi kurulumu için çatı kiralama anlaşması yapılmaktadır. Çatı üzerinde kurulu tesiste üretilen elektrik, elektrik satın alma sözleşmesi çerçevesinde şebekeden alınan elektrik fiyatına göre daha düşük bir bedel üzerinden çatı sahibi tarafından satın alınmaktadır. Üretim tesisinin finansmanı çatıyı kiralayan kişi tarafından karşılanmaktadır. Üretim tesisi belirli bir süre sonunda çatı sahibine devredilmektedir (Karasayar, 2017). Bu itibarla; bu iş modelinin ana iki unsuru, elektrik satın alma sözleşmesi ve finansal kiralamaya dayalı bir üretim tesisi kurulumudur (Overholm, 2015).

Tongsopit, Moungchareon, Aksornkij ve Potisat'ın (2016) da vurguladığı üzere, bu iş modeli sayesinde özellikle enerji tüketimi yüksek olan bina ve sanayi tesisinde elektrik fatura bedelinin, üçüncü bir kişi tarafından çatıya kurulan fotovoltaik sistem sayesinde makul ölçüde azaltılması ve elektrik satın alma sözleşmesi kapsamında belirlenen kurallar çerçevesinde elektrik tedariki ve kazanç sağlanması mümkün olmaktadır. Elektrik satın alma sözleşmesinin süresi 20-25 yıl arasında değişmekte olup üretim tesisinin kurulumu, bakımı ve işletilmesinden üçüncü taraf sorumlu olmaktadır (Drury ve diğerleri, 2012). Bu kapsamda kurulan fotovoltaik sistemlerinden üretilen elektrik şebekeden alınan elektriğe kıyasla yüzde 5 ve 10 arasında daha düşük bedelden çatı sahibine satılmaktadır (Drury ve diğerleri, 2012).

\section{Enerji Kooperatifi}

Enerji kooperatifi modeli; birden fazla kişinin bir araya gelerek tüketimlerini birleştirmeleri esasına dayanmaktadır. Kooperatif sisteminin sağlıklı bir şekilde işlemesi için öngörülebilir bir alım garantisinin olması, düşük faizli borçlanma imkânı ve üretilen elektrikten elde edilen gelirin doğrudan kooperatif tüzel kişiliğine aktarılması yönünde mevzuat altyapısı gerekmektedir (Karasayar, 2017). Bunun yanında Tongsopit ve diğerleri (2016)'ne göre, piyasada güven ortamının sağlanması bakımından kooperatiflere şeffaflık kriterleri çerçevesinde hareket etme zorunluluğu getirilmelidir. Ayrıca kooperatifin nakit akım maliyeti asgari düzeye getirilmeli ve kooperatife vergi teşvikleri uygulanmalıdır. Bu model 
kapsamındaki yatırımları; finansman kurumu, enerji kooperatifi, mühendislik firması ve üretim tesis yeri sahiplerinin katılımı ile gerçekleştirilebilir (Tongsopit ve diğgerleri, 2016).

Türkiye'de yenilenebilir enerji kooperatiflerine yönelik mevzuat altyapısı tamamlanmıştır. Bu tür kooperatifler, tüm tüketim noktaları aynı elektrik dağıtım bölgesi içinde olmak üzere tüketim birleştirme yoluyla ve en az 7 adet aynı tür abone tarafından kurulabilmektedir (Ticaret Bakanlığı, 2019). Kooperatifin elektrik piyasası faaliyetine ilişkin hususlar Elektrik Piyasasında Lisanssız Elektrik Üretim Yönetmeliğinde ayrıntılı bir şekilde düzenlenmiştir.

\section{Paya Dayalı Kitle Fonlaması}

Paya dayalı kitle fonlaması gerek teorik gerek uygulama bakımından yeni bir yöntem olarak karşımıza çıkmaktadır. Bu tür fonlama, son yıllarda gündeme gelen, özellikle ticari ve endüstriyel binaların çatılarında güneş enerjisine dayalı fotovoltaik sistem yatırımlarında internet üzerinden bireysel olarak sağlanan fonlar yoluyla finansman temin edilmesine dayanmaktadır. Bu sistemde fon sağlayan birey önceden belirlenmiş kurallar üzerinden gelir elde eder ve belirli bir sürenin sonunda ödediği bedelin tamamının geri ödemesini alıp devaminda kar elde etmeye başlar (Tongsopit ve diğerleri, 2016).

Bu fonlama türünde üç taraf bulunmaktadır. Bir tarafta proje için fon arayışında olan proje sahipleri, diğer tarafta projeye destek olma talebi bulunan kişiler,üçüncü tarafta ise her iki tarafı karşı karşıya getiren platform yer almaktadır. Gierczak, Bretschneider, Haas, Blohm ve Leimeister'a (2016) göre, projeye destek olan taraf; a) desteği karşılığında bir karşılık almayabilir, b) para dişında bir ödül alabilir, c) desteği karşılığında ürün alabilir, bu şekilde yaptığı katkı üretilecek ürün için bir tür ön ödeme anlamına gelir, ç) desteği kredi şeklinde olup karşılığında faiz alabilir ve son olarak d) proje şirketinden alacağı hisse karşılı̆̆ temettü alabilir.

Türkiye'de paya dayalı kitle fonlamasına ilişkin ikincil mevzuat "Paya Dayalı Kitle Fonlaması Tebliği" 03/10/2019 tarihli ve 30907 sayılı Resmi Gazete'de yayımlanmıştır (Mevzuat Bilgi Sistemi, 2019c). Gözen (2020) tarafından vurgulandığı üzere, bu tebliğ ile Türkiye sermaye piyasasında önemli bir eksiklik giderilmiştir. Bu tebliğ çerçevesinde, yenilenebilir enerji kaynaklarına dayalı yatırımlar için de kullanılabilecek yeni bir model Türkiye'ye kazandırılmış olmaktadır.

\section{Yeşil Tahvil}

Yeşil tahvilin henüz üzerinde uzlaşılan evrensel bir tanımı bulunmamaktadır (DIE, 2016). Diğer tahvillerden farklı olarak, bu tahvil çevreye duyarlı projelere fon sağlamak amacıyla çıkarılan bir finansal araçtır. Banerjee (2019) tarafından vurgulandığı üzere, çevreye duyarlı bir proje yenilenebilir enerji projesi olabileceği gibi enerji verimliliği projesi, düşük karbon emisyonuna sahip ulaşım projesi veya biyoenerji projesi de olabilir.

Yeşil tahvil işlev açısından diğer tahvil türlerine benzemekte, sadece bu yöntemle sağlanan fonun kullanım yeri ile ilgili sınırlamalar bulunmaktadır. Bu tahvil türünde "yeşil proje" ve "yeşil tahvilin niteliği" ön plana çımaktadır. Yeşil proje kapsamına sürdürülebilir çevre konusunu desteklemek amaciyla geliştirilen projeler girmektedir. Gianfrate ve Peri (2019) tarafından yapılan çalışma sonucunda, diğer tahviller ile karşılaştırıldığında yeşil tahvilin uygun bir finansal araç olduğu ve sermaye maliyetinin düşük olduğu ortaya konulmuştur.

Yukarıda açıklandığı üzere, yeşil tahvilin kullanımı belirli yerler ile sınırlı olduğundan bu tür tahviller bazı ilkelere sahiptir. Bu ilkeler nakit akımının kullanımı, proje değerlendirme ve 
seçim süreci, nakit akımının yönetimi ve raporlamadır. Bu ilkeler vasıtasıyla, yeşil tahvilden sağlanan fonun yeşil bir proje için kullanılması, ihraçcı şirketin finansal durumu ve sürdürülebilir çevre konusundaki performansı, fon kullanımına yönelik şeffalığın sağlanması ve ilgili tahvil yatırımcılarının raporlama ile bilgilendirilmesi sağlanmaktadır (Kandır ve Yakar, 2017).

\section{Yenilenebilir Enerji Fonu}

$\mathrm{Bu}$ model; yenilenebilir enerji üretim tesislerinin, özellikle güneş enerjisi sistemlerinin kurulumu için başka faaliyetlerden alınan bedellerden bir fon oluşturulması esasına dayanmaktadır (Karasayar, 2017). Fonun kaynakları idare tarafından talep edenlere veya önceden belirlenen kriterlere uyan yatırımcılara uygun koşullarda kullandırılmaktadır. Fonun kaynaklarının amacı dışında başka alanlarda kullanımı veya fonun kötü yönetilmesi, fondan beklenen faydayı sağlamayacaktır. Bu nedenle, günümüzde fon mekanizmasına yönelik genel algı nedeniyle, bu tür fonun uygulaması sınırlı kalmaktadır.

\section{Tartışma ve Sonuç}

Yukarıda bahsedilen modellerden sabit fiyat garantisinde, idare uygulanacak fiyata odaklanmakta ve bu amaçla ya ilgili mevzuatta ya da idari bir kararla sabit fiyat belirlenmektedir. Bu modelde üretilecek elektrik enerjisi miktarı için bir düzenleme yapılmamakta, miktar tamamen piyasaya bırakılmaktadır. Sabit fiyat garantisi, yenilenebilir enerji kaynaklarından elektrik üretimini artırmakla birlikte teknolojik gelişmeyi de teşvik etmektedir. Bu konuda Almanya ile Danimarka'daki rüzgar türbini üretimindeki gelişmeler örnek gösterilebilir. Bu model, uygulamadan yararlanan ve yararlanmayan yatırımcilar arasında rekabeti bozucu bir etki yaratmakta ve elektrik fiyatında dengesizlik oluşmasına sebep olmaktadır. Nitekim; Ciarreta, Espinosa ve Pizarro-Irızar'ın (2017) belirttiği üzere, sabit fiyat garantisi kapasite artışına yol açmasına rağmen piyasadaki gelişmelere ve fiyat sinyallerine duyarlı bir model değildir.

$\mathrm{Bu}$ nedenle, yenilenebilir enerji kaynaklarından elektrik üretiminin hedeflenen bir düzeye gelmesi veya elektrik üreticileri arasındaki rekabetin arttırılmasından hangisinin enerji politikası açısından önemli olduğunun ortaya konulması gerekmektedir. Günümüzde yeni işletmeye giren tesisler için uygulanan sabit fiyat garantisi tarifelerinde teknolojiye bağlı olarak fiyat azaltılması hususu gündemde olan konuların başında gelmektedir. Diğer taraftan, sabit fiyat garantisi sisteminin organize toptan satış piyasasında klasik üretim tesislerini devre dışı bırakarak arz güvenliğini olumsuz etkilediği sonucuna da varılabilir.

Prim garantisinde destekleme fiyatı kısmen dalgalanmaya bırakılmakta ve sabit bir fiyat uygulanmamaktadır. Prim garantisi, elektrik piyasasının fiyat sinyallerine cevap vermesine, başka bir deyişle, talep yüksek olduğunda veya diğer enerji kaynaklarından yapılan üretimin düşük olması halinde üreticileri elektrik üretmeye teşvik etmektedir. Bu nedenle, yenilenebilir enerji tesislerinin elektrik piyasasına entegrasyonuna daha yüksek oranda katkıda bulunmakta ve bu durum elektrik arzının taleple daha verimli bir şekilde dengelenmesini sağlamaktadır. Ayrıca prim garantisi, yenilenebilir enerji yatırımcıları için piyasa riskini azaltmakta ve asgari gelir miktarı hakkında yatırımcılar adına öngörülebilirlik sağlamaktadır. (European Commission, 2013).

Yeşil sertifikanın sabit fiyat garantisinden en önemli farkı fiyatlama noktasındadır. Yeşil sertifika mekanizmasında fiyat arz ve talebe göre piyasada belirlenmektedir. Bu modelde kota yükümlülüğü önceden belirlenmekte ve genellikle kullanılan teknoloji bakımından bir ayrıma 
gidilmemektedir. Başka bir deyişle, yeşil sertifika mekanizmasında elektrik fiyatı ve elektrik üretim miktarı piyasaya bırakılmaktadır. Sadece yeşil sertifika mekanizmasının usul ve esasları idare tarafından düzenlenmekte ve piyasa işleyişi izlenmektedir. Bu özelliği ile yeşil sertifika mekanizması serbest piyasa şartlarına daha uygun bir model olmaktadır.

Yeşil sertifika sisteminin temel avantajı, yenilenebilir enerjiye yönelik belirlenen politika hedefinin çok düşük maliyetle gerçekleştirilebilmesidir. Bunun altında yatan temel faktör, sertifika fiyatının piyasa katılımcıları tarafından belirlenmesidir. Yükümlü olduğu kotayı yerine getirmek zorunda olan kurumlar, bunu mümkün olan en düşük maliyetle yapmak isteyeceklerdir. Bu durum, elektrik tüketicileri için destek programının maliyetini en aza indirir. Kota yükümlülügünün yerine getirilmemesi halinde uygulanacak cezalar yeterince yüksekse, yenilenebilir enerjiye yönelik politika hedefine ulaşma olasılığı da o derece yüksek olmaktadır. Ayrıca bu modelde; sabit fiyat garantisi uygulamasında görülen, yenilenebilir enerji tesis sayısı ve kapasitesinin kontrolsüz bir şekilde artması riski bulunmamaktadır. Çünkü kota karşılandıktan sonra yenilenebilir enerji tesisinden üretilen elektriği üretmek için bir teşvik bulunmayacaktır (Energypedia, 2019c).

İhale ve açık eksiltme yönteminde, yenilenebilir enerji yatırımını gerçekleştirecek yatırımcı ve bu yatırım için uygulanacak destekleme fiyatı rekabetçi bir mekanizma ile belirlenmektedir. Açık eksiltmede yatırımcı seçiminde fiyat tek kriter iken ihale yönteminde yatırımcı seçiminde fiyat yanında ek kriterler de kullanılmaktadır. Son yıllarda ihale ve açık eksiltme yöntemleri ön plana çıkan modeller olmuştur. Sabit fiyat garantisi ve prim garantisi yerine giderek artan bir şekilde ihale ve açık eksiltme yöntemleri kullanılmaktadır (REN21, 2020).

Proje finansmanında, projenin bizzat kendisi finansman temini için teminat olarak gösterilmektedir. Ancak yenilenebilir enerji projelerinin ilk yatırım maliyetlerinin görece yüksek olması ve kullanılan teknolojide olgunluk seviyesine henüz ulaşılmamış olması, bu projeler için proje finansmanı kapsamında fon temin edilmesini zorlaştırmaktadır. Ancak yukarıda bahsedilen diğer modellerin kullanımının, yenilenebilir enerjiye dayalı projeler için finansman teminini kolaylaştırıcı etkide bulunacağı değerlendirilmektedir.

Net ölçüm uygulamasında sayaç sayısı ve muhasabe kayıtı bakımından tasarruf sağlanır. Ayrıca bu uygulama tüketiciyi enerjiyi verimli kullanmaya teşvik etmektedir. Net faturalama uygulamasının hem tüketici hem de elektrik dağıtım şirketi açısından maksimum faydayı sağlaması için kurulacak tesisin kurulu gücü doğru belirlenmeli, sistemde aşırı yüklenmeye neden olmaması veya üretilen elektriğin sadece ihtiyaç için tüketimi sağlanmalıdır (Tongsopit ve diğerleri, 2016). Net ölçüm yöntemiyle üretimin anlık tüketimden fazla olması durumunda artakalan elektriğin sisteme verilmesi ve bu elektriğin dağıtım şirketince perakende satış fiyatı üzerinden veya alım garantisi kapsamında yüksek bedelden satın alınma yükümlülügüu, nihai tüketici fiyatı üzerinde baskı oluşturacaktır. Bu nedenle; Hagerman, Jaramillo ve Morgan'ın (2016) da belirttiği üzere, alım garantisi kapsamındaki fiyatın piyasa dinamikleri doğrultusunda azaltılarak asgari olarak toptan satış fiyatına endekslenmesi uygun olacaktır.

Sayaç okumasına dayalı tasarım, özellikle güneş enerjisine dayalı küçük ölçekli üretim tesisleri uygun bir yöntem olmaktadır. Bu yönüyle bu tasarımın elektrik tüketicisini üreticiye dönüştürdüğü söylenebilir. Ayrıca elektriğin nakli için gerekli yatırım ihtiyacını azaltması, kayıp ve kaçak oranlarında düşüş yaşanması, bu tasarımın diğer olumlu tarafları olmaktadır.

Dünyanın birçok ülkesinde enerji kooperatifleri, yenilenebilir kaynaklardan elektrik üretimini teşvik etmek amacıyla desteklenmektedir. Bu amaç doğrultusunda, kooperatif uhdesinde 
yenilenebilir kaynaktan üretilen elektrik çoğunlukla sabit fiyat mekanizması ile desteklenmektedir. Enerji kooperatifçiliğinin geliştiği ülkelerde, toplumsal dayanışma bilincinin yüksek olduğu, halkın kendi ihtiyaçlarını ve enerji bağımsızlığına sahip olma isteğinin olduğu görülmektedir. Bu farkındalık sayesinde, enerji kooperatiflerinin enerji alanında faaliyet gösterebildiği görülmüsstür (Ticaret Bakanlı̆̆1, 2019). Özellikle Avrupa kıtasında enerji ve kooperatifçilik politikaları ile uyumlu olarak uygulanan teşvikler, enerji kooperatifinin gelişimi için itici güç olmaktadır. Danimarka ve Almanya'nın bu konudaki uzun süreli başarısının altında sabit fiyat uygulaması olduğu bilinmektedir (Ticaret Bakanlığı, 2019).

Paya dayalı kitle fonlamasında, toplanan fonların ilgili proje ve amaca uygun olarak kullanıldığının kontrolü ve denetimi, yaptırım mekanizması ve fon sağlayanların haklarının korunması önem arzetmektedir. Bu konuda sermaye piyasasını düzenleme ve denetleme ile görevli idareye önemli görev düşmektedir. Fon toplanması için internet ortamı kullanıldığından, fon sağlayıcıların elektronik ortamda yapılan işlemlere duyduğu güvenin artırılması gerekmektedir. Bu model, ticari ve endüstriyel çatılarda veya arazi uygulamalarında elektrik üretim tesisi kurulması ve üretilen elektriğin tamamının sisteme satılmasıyla elde edilen gelire dayalı bir iş modeli olarak uygulanabilir. $\mathrm{Bu}$ fonların yatırımcılar için, menkul kıymet yatırımlarına alternatif ve daha az riskli olması ve ayrıca çevresel etkilerin giderilmesine olumlu katkı sağlaması nedenleriyle kabul edilebilir bir yatırım aracı olduğu düşünülmektedir. Ancak yukarıda belirtilen hususlardaki belirsizlik ve risk bu modelin en önemli dezavantajı olarak görülmektedir.

Yenilenebilir enerji fonu, ancak fonlardan sağlanan finansmanın uygun şartlarda kullanımı halinde faydalı olacaktır. Finansman çerçevesinde geri ödeme süresi ve faiz oranları belirlenirken piyasa şartları dikkate alınarak mühendislik firmalarından performans belgeleri istenmeli ve ekonomik bakımdan fizibiliteleri rasyonel bulunan projelere fon sağlanmalıdır. Aksi takdirde kötüye kullanım söz konusu olabilecektir. Bu modelde elde edilen gelir çatı sahibine aktarıldığı için, bu modelin toplum tarafından kabul görmesi daha kolay görünmektedir (Tongsopit ve diğerleri, 2016). Bu modelde herhangi bir alım garantisi modeline gerek olmaksızın güneş enerjisine dayalı üretim tesisi kapasitesinde artış sağlanabileceği düşünülmektedir. Ancak kamu bankalarının öncü olarak bu fonlar için teşvik edici girişimlerde bulunmaları durumunda diğer bankaların da benzer fonlar oluşturması sağlanarak kapasite geliştirme süreci güçlendirilebilecektir.

Yeşil tahvil, yeni bir tahvil türü olup bu kapsamda toplanan fonun başka alanlarda başka amaçlar için kullanılıp kullanılmadığının izlenmesi önemli bir husustur. Ayrıca yeşil tahvil niteliğinin net bir şekilde ortaya konması ve şeffalık ilkesi çerçevesinde yatırımcıya bilgi verilmesi, uygulama bakımından olmazsa olmaz bir unsurdur.

Özetlemek gerekirse, yenilenebilir enerji projeleri için mevcut durumda farklı yatırım ve finansman modelleri uygulanmaktadır. Bu modellerden sabit fiyat garantisi, prim garantisi ve yeşil sertifika tek başına ya da diğer modeller ile birlikte uygulanabilme özelliğine sahiptir. Ayrıca paya dayalı kitle fonlaması ve yeşil tahvil uygulaması, söz konusu üç modele bağlı olmaksızın uygulanabilecek modeller olarak dikkat çekmektedir. Söz konusu modellerin uygulanma sıklığı hakkında genel bir değerlendirme yapmanın mümkün olmadığ değerlendirilmektedir. Çünkü piyasadaki gelişme ve değişen ekonomik koşullar dikkate alındığında uygulanan modellerin zamanla değiştirilmesi gerekmektedir. Nitekim dünya uygulamaları dikkate alındığında, piyasada rekabetin tesisi ve diğer taraftan tüketicinin 
üzerindeki yükün azaltılması amaçlarıyla sabit fiyat garantisi ve prim garantisi yerine ihale ve açık eksiltme modelleri giderek artan bir şekilde kullanılmaktadır. Bunun yanında küçük ölçekli üretim tesislerinin teşvik edilmesi, enerjinin tüketildiği yerde üretilmesi, kayıp-kaçak oranlarının düşürülmesi ve elektrik şebeke yatırım ihtiyacının azaltılması amaçlarıyla sayaç ölçümüne dayalı piyasa tasarımının tercih edildiği görülmektedir.

\section{Teşekkür ve Bilgilendirme}

Bu çalışma, Vedat Akdağ tarafından 2019 yılında Enerji Piyasası Düzenleme Kurumunda tamamlanan “Enerji Piyasasında Yenilenebilir Enerji Kaynaklarına Dayalı Elektrik Üretim Yatırımlarına Yönelik İş Modelleri ve Finansman Yöntemlerinin Düzenleme Perspektifinden İncelenmesi" başlıklı uzmanlık tezi baz alınarak hazırlanmış ve daha kapsamlı literatür taramasıly geliştirilmiştir.

\section{Kaynakça}

Abdmouleh, Z., Alammari, R.A.M., \& Gastli, A. (2015). Recommendations on renewable energy policies for the GCC countries. Renewable \& Sustainable Energy Reviews, 50, 11811191. DOI:10.1016/j.rser.2015.05.057

Abolhosseini, S., \& Heshmati, A. (2014). The main support mechanisms to finance renewable energy development, IZA Discussion Paper No. 8182. Retrieved from https://papers.ssrn.com/sol3/ papers.cfm?abstract_id $=2441478$

Akdağ, V., Gözen, M. (2019). Yenilenebilir enerji projelerine yönelik güncel yatırım ve finansman modelleri: Seçilmiş ülke örnekleri üzerinden bir değerlendirme. İzmir Demokrasi Üniversitesi Sosyal Bilimler Dergisi, 2019, 2(2), 138-172.

Bahar, H., Jagoda, E., \& Steenblik, R. (2013). Domestic incentive measures for renewable energy with possible trade implications, OECD Trade and Environment Paper No. 2013/01. Retrieved from http://www.oecd.org/officialdocuments

Banerjee, A. (2019). Financing the climate change through green (climate sustainable) bonds, 2019 Advances in Science and Engineering Technology International Conferences, 1-4. DOI:10. 1109/ICASET.2019.8714408

Beck, F., \& Martinot, E. (2004). Renewable energy policies and barriers. Encyclopedia of Energy, 5, 267. Retrieved from http://www.martinot.info/Beck_Martinot_AP.pdf

Ciarreta, A., Espinosa, M.P., \& Pizarro-Irızar, C. (2017). Optimal regulation of renewable energy: A comparison of feed-in tariffs and tradable green certificates in the Spanish electricity system. Energy economics, 67(2017): 387-399. DOI:10.1016/j.eneco.2017.08.028

Comello, S., \& Reichelstein, S. (2017). Cost competitiveness of residential solar PV: The impact of net metering restrictions. Renewable and Sustainable Energy Reviews, 75 (May 2016), 46-57. DOI:10.1016/j.rser.2016.10.050

Couture, T.D., Cory, K., Kreycik, C., \& Williams, E. (2010). A policymaker's guide to feed-in tariff policy design, Technical Report NREL/TP-6A2-44849. Retrieved from https://www.nrel.gov/ docs/fy10osti/44849.pdf

Deutsche Bank AG (2010). Global energy transfer feed-in tariffs for developing countries. Retrieved from https://institutional.dws.com/content/media/GET_FIT-_042610_FINAL.pdf 
DIE (2016). Green bonds: Taking off the rose-coloured glasses. Briefing paper 24/2016. Retrieved from https://www.die-gdi.de/briefing-paper/article/green-bonds-taking-off-the-rose-colou red-glasses

Donastorg, A., Renukappa, S., \& Suresh, S. (2017). Financing renewable energy projects in developing countries: A critical review. IOP Conference Series Earth and Environmental Science, 83(1). DOI:10.1088/1755-1315/83/1/012012

DSIRE (2019). Database of State Incentives for Renewables \& Efficiency. Retrieved from http:// www.dsireusa.org/solar/solarpolicyguide/?id=17

Eid, C., Guillén, J.R., Marín, P.F., \& Hakvoort, R. (2014). The economic effect of electricity netmetering with solar PV: Consequences for network cost recovery, cross subsidies and policy objectives. Energy Policy, 75, 244-254. DOI:10.1016/j.enpol.2014.09.011

Energypedia (2019a). Feed-in tariffs (FIT). Retrieved from https://energypedia. info/wiki/Feedin_Tariffs_(FIT)

Energypedia (2019b). Feed-in premiums (FIP). Retrieved from https://energypedia.info/wiki/ Feed-in_Premiums_(FIP)

Energypedia (2019c). Renewable energy quota and certificate schemes. Retrieved from https:// energypedia.info/wiki/Renewable_Energy_Quota_and_Certificate_Schemes

Energypedia (2019ç). Renewable energy tendering schemes. Retrieved from https://energy pedia.info/wiki/Renewable_Energy_Tendering_Schemes

Energypedia (2019d). Renewable energy quota and certificate schemes. Retrieved from https:// energypedia.info/wiki/Renewable_Energy_Quota_and_Certificate_Schemes

European Commission (2013). Commission staff working document European Commission guidance for the design of renewables support schemes. Retrieved from https://ec.europa.eu/energy/ sites/ener/files/documents/com_2013_public_intervention_swd04_en.pdf

Gianfrate, G., \& Peri, M. (2019). Exploring the convenience of issuing green bonds. Journal of cleaner production, 219(2019): 127-135. DOI:10.1016/j.jclepro.2019.02.022

Gierczak, M.M., Bretschneider, U., Haas, P., Blohm, I., \& Leimeister, J.M. (2016). Crowdfunding: Outlining the new era of fundraising. Eds. Brüntje, D. \& Gajda, O., Crowdfunding in Europe: State of the art in theory and practice. New York: Springer, 7-24.

Gözen, M. (2020). Paya dayalı kitle fonlaması: Türkiye'deki mevzuat ve işleyiş̧in incelenmesi. Sosyal, Beşeri ve İdari Bilimler Alanında Akademik Çalışmalar - 1, Gece Kitaplı̆̆ı, Ankara, 15-34.

Gözen, M., \& Durak, S. (2003). Yenilenebilir Enerji Kaynaklarından Elektrik Üretimine Yönelik Piyasa Düzenlemeleri ve Teşvik Uygulamaları, Retrieved from http://www.emo.org.tr/ekler/ 6dce5f2f0e61edbek.pdf

Hagerman, S., Jaramillo, P., \& Morgan, M.G. (2016). Is rooftop solar PV at socket parity without subsidies? Energy Policy, 89, 84-94. DOI:10.1016/j.enpol.2015.11.017

IEA (2014). Net metering code: for connecting renewable energy generating systems to the distribution system in Ghana. Retrieved from https://www.iea.org/media/pams/ghana/NetMeteringCo deGhanaAug.2014.pdf 
Kandır, S.Y., \& Yakar, S. (2017). Yenilenebilir enerji yatırımları için yeni bir finansal araç: Yeşil tahviller. Maliye Dergisi, 172: 85-110.

Karasayar, C. (2017). Güneş enerjisinde çatı uygulamalarının dünya genelinde incelenmesi ve Türkiye'de gelişimini sağlamak için öneriler (Enerji uzmanlık tezi, Enerji Piyasası Düzenleme Kurumu, Ankara).

Lind, A., \& Rosenberg, E. (2014). How do various risk factors influence the green certificate market of Norway and Sweden? Energy Procedia, 58(2014): 9-15. DOI:10.1016/j.egypro. 2014.10.402

Liptow, H., \& Remler, S. (2012). Legal frameworks for renewable energy - Policy analysis for 15 developing and emerging countries. Bonn, Eschborn Deutsche Gesellschaft für Internationale Zusammenarbeit (GIZ) GmbH. Retrieved from https://www.icafrica.org/fileadmin/docu ments/Knowledge/GIZ/Legal\%20Frameworks\%20for\%20Renewable\%20Energy.pdf

Lucas, H., Ferroukhi, R., \& Hawila, D. (2013). Renewable energy auctions in developing countries. Abu Dhabi: IRENA Publications.

Mevzuat Bilgi Sistemi (2019a). 5346 sayıl Yenilenebilir Enerji Kaynaklarının Elektrik Enerjisi Üretimi Amaçh Kullanımına İlişkin Kanun. Erişim adresi: https://www.mevzuat.gov.tr

Mevzuat Bilgi Sistemi (2019b). Yenilenebilir Enerji Kaynak Alanları Yönetmeliği. Erişim adresi: https://www.mevzuat.gov.tr

Mevzuat Bilgi Sistemi (2019c). Paya dayalı kitle fonlaması tebliğgi (III-35/A.1). Erişim adresi: https: //www.mevzuat.gov.tr

Mevzuat Bilgi Sistemi (2020). Elektrik Piyasasında Lisanssız Elektrik Üretim Yönetmeliği. Erişim adresi: https://www.mevzuat.gov.tr

NREL, National Renewable Energy Laboratory (2019). Simple Levelized Cost of Energy (LCOE) Calculator Document. Retrieved from http://www.nrel.gov

Overholm, H. (2015). Spreading the rooftop revolution: What policies enable solar-as-aservice? Energy Policy, 84, 69-79. DOI:10.1016/j.enpol.2015.04.021

REN21 (2018). Renewables 2018 global status report. Retrieved from http://www.ren21.net

REN21 (2020). Renewables 2020 global status report. Retrieved from http://www.ren21.net

Rickerson, W., Laurent, C., Jacobs, D., Dietrich, C., \& Hanley, C. (2012). Feed in tariffs as a policy instrument for promoting renewable energies and green economies in developing countries. Retrieved from https://unfccc.int/files/documentation/submissionsfromparties

Ticaret Bakanlığı (2019). Yenilenebilir Enerji Kooperatifleri. Erişim adresi: https://www.ticaret. gov.tr/kooperatifcilik/bilgi-bankasi

Tongsopit, S., Moungchareon, S., Aksornkij, A., \& Potisat, T. (2016). Business models and financing options for a rapid scale-up of rooftop solar power systems in Thailand. Energy Policy, 95: 447-457. DOI:10.1016/j.enpol.2016.01.023 